\title{
Pulmonary Hamartoma
}

\section{TAPAN DAS BAIRAGYA, ${ }^{1}$ SIBES KUMAR DAS, ${ }^{2}$ SOMNATH BHATTACHARAYA ${ }^{3}$}

A 62- year- old non smoker female patient presented after having a routine chest radiograph prior to hysterectomy. She did not have any respiratory symptoms. On enquiry regarding her past illness she denies any history of pulmonary tuberculosis. She recalled that a chest radiograph performed 10 years back also had shown an abnormality. Her general examination was absolutely normal.Routine blood tests and pulmonary function tests were all normal. The PAChest radiograph show an approximately $4 \mathrm{~cm}$ heavily calcified lesion in the left mid zone with typical 'popcorntype' calcification of a pulmonary hamartomas (Figure-1 \& 2)

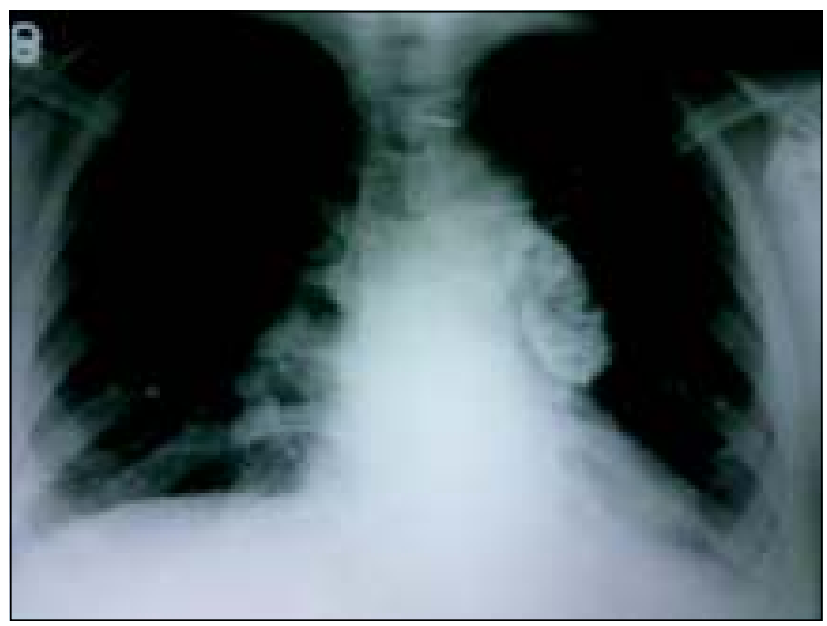

Fig.-1: Chest X ray (PA View) showing heavily calcified lesion in the left mid zone with typical 'popcorn-type' calcification of a pulmonary hamartomas.

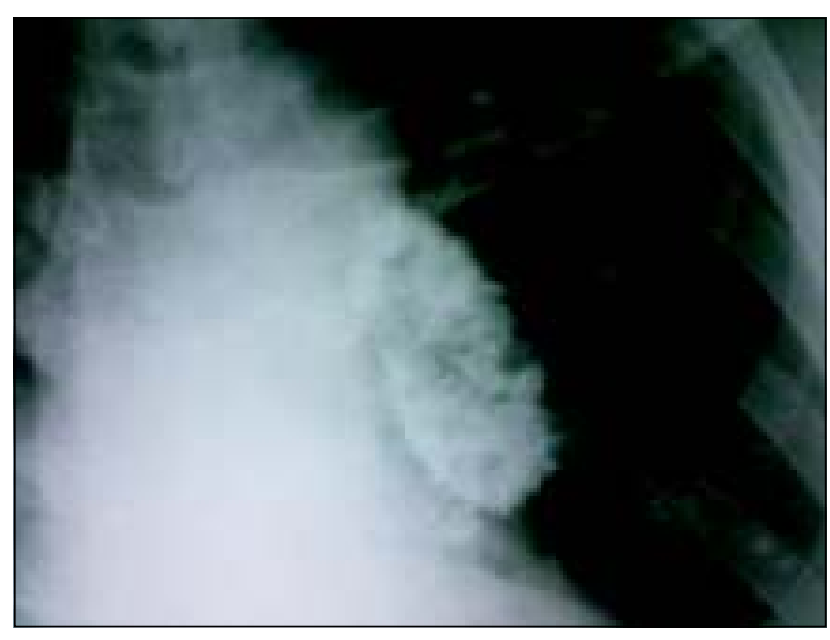

Fig.-2: The lesion showing typical 'popcorn-type' calcification in radiograph.

Hamartomas are usually asymptomatic and most are found in the 6th to 7 th decades . ${ }^{1}$ Pulmonary hamartomas can be up to $10 \mathrm{~cm}$ in diameter. Larger the lesion more likely to it is to calcify. Characteristic punctate or popcorn calcification occurs on plain films in about $10 \%$ of cases.$^{2}$ As these lesions are benign, no further investigation done.

\section{Conflict of Interest: None}

\section{References:}

1. Gjevre J, Myers J, Prakash U. Pulmonary hamartomas. Mayo Clin Proc 1996; 71:14-20

2. Fudge T, Ochsner J, Mills N. Clinical spectrum of pulmonary hamartomas. Ann Thorac Surg 1980; 30:36-39.

1. RMO cum Clinical Tutor, Department of Respiratory Medicine. North Bengal Medical College, Darjeeling, West Bengal, India

2. Associate Professor, Department of Respiratory Medicine. CMC,Kolkata .West Bengal, India

3. . Assistant Professor, Department of Respiratory Medicine. North Bengal Medical College, Darjeeling, West Bengal, India

Correspondence: Tapan Das Bairagya, RMO cum Clinical Tutor, Department of Respiratory Medicine. North Bengal Medical College, Darjeeling, West Bengal, India 